\title{
Acute effect of aerobic dance exercise on blood pressure of normotensive pregnant Nigerian women
}

\author{
Daniel J. A. ${ }^{1 *}$, Nwaogu E. I. ${ }^{1}$, Okoli S. C. ${ }^{1}$ and Nzeribe E. A. ${ }^{2}$ \\ ${ }^{1}$ Physiotherapy Department, Federal Medical Centre, Owerri, Imo State, Nigeria. \\ ${ }^{2}$ Department of Obstetrics and Gynaecology, Federal Medical Centre, Owerri, Imo State, Nigeria.
}

Accepted 4 February, 2019

\begin{abstract}
Exercise has been shown to reduce blood pressure (BP) in hypertensive patients. However, studies reporting reduced BP from chronic exercises might disregard an acute effect exercise could have on BP. Aerobic dance is one of the commonly recommended exercises for pregnant women without complications. The study aims to determine the acute effect of aerobic dance exercise of moderate intensity, on the BP of normotensive pregnant women. Pre-test/post-test research design involving 24 pregnant women of not less than 12 weeks gestation who volunteered from among women attending antenatal clinic at the Federal Medical Centre, Owerri, Nigeria. The women were screened and met the inclusion criteria, had their Systolic and Diastolic blood pressures (SBP and DBP) measured before participating in an exercise. The SBP and DBP were measured again at the end of the exercise and finally after 30 min rest. Data was analysed using Repeated ANOVA. SBP changed significantly between pre-exercise and $30 \mathrm{~min}$ post exercise rest but not between Pre-exercise and after 30 min exercise. DBP decreased significantly from pre-exercise to $30 \mathrm{~min}$ post exercise rest but not between after $30 \mathrm{~min}$ exercise and $30 \mathrm{~min}$ post exercise rest. In conclusion, moderate intensity aerobic dance exercise did not precipitate adverse acute cardiovascular response. Aerobic dance may be effective in management of hypertension in pregnancy.
\end{abstract}

Keywords: Aerobic dance, blood pressure response, antenatal exercise, acute effect.

*Corresponding author. E-mail: dchrisjovys@yahoo.com. Tel: 08064774481.

\section{INTRODUCTION}

Fear of possible adverse effects has remained one of the major obstacles to exercise participation among pregnant women despite assurances from various research outcomes in this area. As the number of pregnant women who want to participate in sports activities continues to increase, questions about the safety and benefit of maternal exercise for the mother and fetus become more important (Perales et al., 2015).

Several researchers suggested that there is a training effect from participating in an ongoing exercise program and that exercise may help to maintain work efficiency at pre-pregnancy levels despite the demands of the pregnancy (Carpenter et al., 1988; Shrock, 2008; Danforth, 1967). Exercise has been shown in numerous studies to be safe in pregnancy, and is recommended by the American College of Obstetrics and Gynecology (ACOG) as part of routine prenatal care. However, aerobic exercise can be viewed by patients to be difficult to perform during pregnancy, particularly when the patient is obese and at later gestations. Exercise is a stressor, likewise pregnancy and it is a common fear among healthcare providers that exercising in pregnancy may increase the stress experienced by pregnant women.

Exercise is recommended for pregnant women who exhibit none of the conditions contradicting exercising in pregnancy as stipulated in ACOG guideline (Artal and O'Toole, 2003) for exercising in pregnancy. Exercise have been shown to improve maternal cardiovascular function, control weight gain and fat retention, improve 
insulin resistance, curb onset of gestational diabetes, improve blood glucose level in gestational diabetes (Daniel et al., 2014) and reduce postpartum depression. It is important to note that different individuals respond differently to exertion and response could also depend on the exercise mode and intensity, as well as duration. When pregnant women exercise, cardiovascular and respiratory responses naturally increase. Systolic blood pressure rises from 30 to $40 \mathrm{mmHg}$, whereas the diastolic blood pressure rises only $10 \mathrm{mmHg}$ with exercise (Shrock, 2008). However, the BP is expected to reduce gradually to pre-exercise value following rest. The importance of physical exercise in promoting a reduction in resting BP levels is well established in the academic literature (Nascimento et al., 2017; Blumenthal et al., 2000) and is a phenomenon known as post-exercise hypotension (PEH) [Kenney and Seals, 1993]. PEH could occur due to alterations in diverse mechanisms such as reduced peripheral vascular resistance and/ or cardiac output (Hara and Floras, 1995; Halliwill, 2001; Rueckert et al., 1996), increased vasodilator bioavailability (Halliwill, 2001; Lockwood et al., 2005; Higashi et al., 1999), reduced sympathetic nerve activity, increased parasympathetic modulation and improved baroreflex sensitivity (Pober et al., 2004; Halliwill et al., 2013). In a meta-analysis of normotensive and hypertensive patients, Fagard (2006) showed a $3.3-\mathrm{mmHg}$ decrease in SBP, and $3.5 \mathrm{mmHg}$ for DBP. Such reductions in chronic levels are often more discreet, but very important clinically, where a $2-\mathrm{mmHg}$ reduction may decrease the risk of myocardial infarction by about $6 \%$, and the risk of developing coronary artery disease by $4 \%$ (Chobanian et al., 2003 ).

It should also be noted that some activities carry more risk than others (Daniel, 2008) and discomfort from exercise increases as gestational age increases. It is very important to choose safe exercises for pregnant women in order to avert all potential harms arising from exercise, on either the mother or the fetus (Carpenter et al., 1990).

Some researchers have reassured pregnant women that engaging in antenatal exercises may not precipitate preterm labour and delivery, (Daniel et al., 2015) but few work have been done in the area of studying the acute effect of some of the commonly recommended exercises on the cardiovascular system of these pregnant women.

Aerobic dance is one of the exercises assumed to be very safe for pregnant women and so is about one of the most recommended exercise by healthcare provider during antenatal health talk. Aerobic dance could be seen and perceived as safe but there is also need to find out if it really has any significant benefit on the cardiovascular system of the women. It is also necessary to rule out any possible adverse effect on the mother and fetus from participating in this mode of exercise.

This study monitored the acute response of the blood pressure of normotensive pregnant women to aerobic dance exercise and recovery pattern of same women after termination of the exercise.

\section{MATERIALS AND METHODS}

\section{Study design and subjects}

This is a pretest/posttest study design in which a total of 33 pregnant women attending antenatal clinic at the Federal Medical Centre, Owerri, Nigeria indicated interest to participate in the study. The subjects volunteered to participate without any form of inducement or persuasion. They were screened for any of the conditions contraindicating participation in antenatal exercises as stipulated in ACOG (Artal and O'Toole, 2003). As outlined by ACOG, these conditions include heart disease, toxemia, ruptured membranes, risk of premature labor, intrauterine growth retardation, poor weight gain, vaginal or uterine bleeding, anemia, hypertension, and fetal distress. Consultation with health care providers or some degree of caution is necessary for expectant women with respiratory conditions such as asthma or orthopedic conditions such as back and hip pain or joint problems. Screening was carried out using Physical Activity Readiness Medical Examination questionnaire. Twenty nine (29) of them met the inclusion criteria and were recruited for the study. They were required to read and sign inform consent form after being adequately informed of the purpose and procedure of the study. Only women who were pregnant and not less than 16 weeks of gestation were allowed to participate in this study. This is to rule out complications of first trimester such as nausea and vomiting and possible abortion as a result of stress of the exercise. Both primaparous and multiparous mothers were allowed to participate in the study. None of the subjects was previously involved in any form of exercise programme as that was one of the inclusion criteria.

Blood pressure of participants were measured and documented prior to commencement of Exercise programme using NZ 009 Arm Automatic blood pressure monitor, after 10 minutes rest in upright sitting position. Participants were put through a warm up exercise in form of low intensity aerobic dance to a beat of a slow music. The warm up exercise was maintained at intensity of 11 to 12 on Borg Scale of Perceived Exertion. After 5 min warm up, the music was changed to a faster track of a pre-recorded beat that made the women dance at an intensity corresponding to13 to 14 on the Borg Scale of perceived exertion. The dance pattern was demonstrated by the coach who is a trained Physiotherapist and Exercise Physiologist. They sang along as they danced, as a familiar music tone was used. The participants danced for $20 \mathrm{~min}$ and then, the music was switched back to the slow music as cool down for 5 min.

The blood pressure was taken again and documented at the end of the $30 \mathrm{~min}$ dance exercise. Participants were allowed to rest for $30 \mathrm{~min}$ and then the final reading of their blood pressure was taken. All statistical analyses were performed on IBM compatible microcomputer, using the statistical package for social science (SPSS) (window version 17.0 Chigaco IL.USA). One way Repeated ANOVA was employed to analyse the data. Descriptive statistics of Means and Standard Deviation were computed and presented in the result section of this article. The probability level was set at 0.05 .

\section{RESULTS}

Five (5) of the women could not complete the study as they could not participate in the aerobic dance to the end of the $30 \mathrm{~min}$ and so their data were not included in the analysis as their data were incomplete. Data from 24 participants who completed the $30 \mathrm{~min}$ exercise programme were analysed.

Table 1 shows information regarding to the demographic characteristics of the participants. The information shown are; maternal age, height, weight, 
Table 1. Demographic information of participants.

\begin{tabular}{lccccc}
\hline & Minimum & Maximum & Mean & Std. Deviation & N \\
\hline Maternal age & 20 & 36 & 28.67 & 3.50 & 24 \\
Gestational age (weeks) & 17 & 40 & 29.88 & 5.77 & 24 \\
Pregnancy Body Mass Index (BMI) & 20.0 & 45.0 & 29.19 & 5.86 & 24 \\
Maternal weight & 55.00 & 121.00 & 80.21 & 16.08 & 24 \\
Maternal height & 1.54 & 1.92 & 1.66 & .08 & 24 \\
\hline
\end{tabular}

$\mathrm{BMI}$, gestational age.

Table 2 shows the mean and standard deviation of the systolic blood pressure, showing SBP increasing from $116.62 \pm 11.82 \mathrm{mmHg}$ pre exercise value to $122.75 \pm$ $14.84 \mathrm{mmHg}$ after $30 \mathrm{~min}$ of exercise and then reducing to $109 \pm 10.79 \mathrm{mmHg}$ after $30 \mathrm{~min}$ post exercise rest.

A One-way repeated ANOVA was conducted to determine if there was statistically significant difference in the SBP of the pregnant women following a $30 \mathrm{~min}$ aerobic dance exercise. There were no outliers and data was normally distributed as assessed by Shapiro-Wilk test $(P>.05)$. The assumption of sphericity was not violated as assessed by Mauchly's test of sphericity, $X^{2}(2)=5.076, P=.079$.

The SBP was statistically significantly different at the different times of recording; Pre Exercise, After 30 minutes Exercise and After 30 min post exercise rest., $F(2,46)=15.67, P<.0005$ (Table 3).

Post hoc analysis with Bonferroni adjustment revealed the SDP was statistically non significantly increased from pre exercise to after $30 \mathrm{~min}$ exercise $[6.13(95 \% \mathrm{Cl}$, 0.634 to 12.88$) \mathrm{mmHg}, P=.085]$ but decreased statistically significantly from after $30 \mathrm{~min}$ exercise to after 30 min post exercise rest $[12.83(95 \% \mathrm{Cl}, 17.25$ to 8.42$)$ $\mathrm{mmHg}, \mathrm{P}=.001]$ and from pre exercise to after $30 \mathrm{~min}$ post exercise rest $[6.708(95 \% \mathrm{Cl}, 13.03$ to 0.39$) \mathrm{mmHg}$, $\mathrm{P}=.035]$ (Table 4).

The mean and standard deviation of the diastolic blood pressure showed slight increase in the DBP from $68.54 \pm$ $9.56 \mathrm{mmHg}$ pre exercise to $68.58 \pm 9.99 \mathrm{mmHg}$ after 30 min of exercise which is non-significant, and then decreased to $64.54 \pm 6.41 \mathrm{mmHg}$ after $30 \mathrm{~min}$ post exercise rest (Table 5).

A one-way repeated ANOVA was conducted to determine if there was statistically significant difference in the DBP of the pregnant women following a 30 minutes aerobic dance exercise (Table 6). There were no outliers and data was normally distributed as assessed by Shapiro-Wilk test $(P>.05)$. The assumption of sphericity was not violated as assessed by Mauchly's test of sphericity, $X^{2}(2)=2.041, P=.360$.

There was statistically significant changes in the DBP of the women from the pre-exercise through $30 \mathrm{~min}$ exercise to after 30 min post exercise rest, $F(2,46)=$ 3.39, $\mathrm{P}=.04$.

Post hoc analysis with Bonferroni adjustment revealed there was statistically no significant change in the DBP from pre-exercise to after 30 min exercise, with increase of about $0.042(95 \% \mathrm{Cl},-4.92$ to 4.84$) \mathrm{mmHg}, \mathrm{P}=1.000$ (Table 7). There was also no statistically significant change in the DBP from after $30 \mathrm{~min}$ exercise to after 30 min post exercise rest, $4.042(95 \% \mathrm{Cl}, .940$ to 9.024$)$ $\mathrm{mmHg}, \mathrm{P}=.142$. There was however, a statistically significant decrease in the DBP from pre-exercise to after 30 min post exercise rest, $4.000(95 \% \mathrm{Cl}, .139$ to 7.861$)$ $\mathrm{mmHg}, \mathrm{P}=.041$.

Table 2. Descriptive statistics of systolic blood pressure (SBP).

\begin{tabular}{lccc}
\hline Parameter & Mean & Std. deviation & N \\
\hline Pre-exercise & 116.62 & 11.817 & 24 \\
After 30 min exercise & 122.75 & 14.836 & 24 \\
After 30 min post exercise rest & 109.92 & 10.786 & 24 \\
\hline
\end{tabular}

Table 3. One-way repeated ANOVA of the SBP.

\begin{tabular}{lccccc}
\hline Source & SS & df & MS & F & Sig. \\
\hline Sphericity assumed & 1977.69 & 2 & 988.85 & 15.67 & .001 \\
Error & 2902.31 & 46 & 63.09 & & \\
\hline
\end{tabular}


Table 4. Bonferroni post-hoc test for SBP.

\begin{tabular}{|c|c|c|c|c|c|c|}
\hline \multirow{2}{*}{ I } & \multirow{2}{*}{$\mathbf{J}$} & \multirow{2}{*}{ Mean difference (I-J) } & \multirow{2}{*}{ Std. error } & \multirow{2}{*}{ Sig. } & \multicolumn{2}{|c|}{$95 \% \mathrm{Cl}$} \\
\hline & & & & & Lower bond & Upper bond \\
\hline \multirow{2}{*}{1} & 2 & -6.13 & 2.62 & .085 & -12.88 & .634 \\
\hline & 3 & 6.71 & 2.45 & .035 & .039 & 13.03 \\
\hline \multirow{2}{*}{2} & 1 & 6.13 & 2.62 & .085 & -634 & 12.88 \\
\hline & 3 & 12.83 & 1.71 & .000 & 8.42 & 17.25 \\
\hline \multirow{2}{*}{3} & 1 & -6.71 & 2.45 & .035 & -13.03 & -3.85 \\
\hline & 2 & 12.83 & 1.71 & .000 & -17.25 & -8.42 \\
\hline
\end{tabular}

Table 5. Descriptive statistics of diastolic blood pressure (DBP).

\begin{tabular}{llcc}
\hline Parameter & Mean & Std. deviation & N \\
\hline Pre-exercise DBP & 68.54 & 9.564 & 24 \\
Within exercise after 30 min exercise & 68.58 & 9.987 & 24 \\
30 min post exercise rest & 64.54 & 6.413 & 24 \\
\hline
\end{tabular}

Table 6. One-way repeated ANOVA of the DBP.

\begin{tabular}{lccccc}
\hline Source & SS & df & MS & F & Sig. \\
\hline Sphericity assumed & 258.69 & 2 & 129.34 & 3.39 & .042 \\
Error & 1753.97 & 46 & 63.09 & & \\
\hline
\end{tabular}

Table 7. Bonferroni post-hoc test for DBP.

\begin{tabular}{|c|c|c|c|c|c|c|}
\hline \multirow{2}{*}{ I } & \multirow{2}{*}{$\mathbf{J}$} & \multirow{2}{*}{ Mean difference (I-J) } & \multirow{2}{*}{ Std. error } & \multirow{2}{*}{ Sig. } & \multicolumn{2}{|c|}{$95 \% \mathrm{Cl}$} \\
\hline & & & & & Lower bond & Upper bond \\
\hline \multirow{2}{*}{1} & 2 & -.042 & 1.89 & 1.000 & -4.923 & 4.840 \\
\hline & 3 & 4.00 & 1.50 & .041 & .139 & 7.861 \\
\hline \multirow{2}{*}{2} & 1 & .042 & 1.89 & 1.000 & -4.840 & 4.923 \\
\hline & 3 & 4.04 & 1.93 & .142 & -.940 & 9.024 \\
\hline \multirow{2}{*}{3} & 1 & -4.00 & 1.50 & .041 & -7.861 & -139 \\
\hline & 2 & -4.04 & 1.93 & .142 & -9.024 & .940 \\
\hline
\end{tabular}

\section{DISCUSSION}

No previous study to our knowledge has been carried out to see the acute effect of exercise on the blood pressure of normotensive pregnant women. Previous studies concentrated on chronic effect of exercise on blood pressure and most of them reported decrease in BP after some weeks or months of exercise programme (CarpiroRivera et al., 2016). Our study looked at the acute effect of exercise in pregnant women.

The data from our study showed that there was an increase in the SBP, which was not statistically significant, following 30 minutes aerobic dance exercise. However, there was significant decrease in the blood pressures after $30 \mathrm{~min}$ rest following termination of exercise. The increase in SBP was not statistically significant but the decrease after $30 \mathrm{~min}$ rest was significantly below the pre exercise and after $30 \mathrm{~min}$ exercise values. We also recorded a significant decrease in the diastolic BP after $30 \mathrm{~min}$ rest, post exercise, $(\mathrm{P}=.041$.), when compared to the pre exercise value. The recovery pattern of the women was normal and tallies 
with findings of a meta-analysis by Carpio-Rivera et al. (2016).

Other studies have also found decreased BP levels after a single aerobic exercise session for hypertensive patients (Pescatello et al., 2007; Park et al., 2006; Quinn, 2000). There is a wide range of magnitude (between -2 and $-12 \mathrm{mmHg}$ ) and duration (between 4 and $16 \mathrm{~h}$ ) of $\mathrm{PEH}$, which is probably due to individual characteristics and different aerobic exercise protocols (e.g., intensity and duration) (Cardoso et al., 2010). BP reduction is also found in follow-up studies (Pinto et al., 2006; Moreira et al., 1999). A study hypothesized that short-term sessions of aerobic exercise of mild, moderate and high intensities can promote $\mathrm{PEH}$ as a primary outcome; furthermore, follow-up aerobic exercise training for 8 weeks can reduce the BP levels.

We recorded a decrease of $6.7 \mathrm{mmHg}$ in the SBP and epidemiological studies indicate that a decrease of 2 $\mathrm{mmHg}$ in the SBP is likely to reduce the mortality associated with stroke by $6 \%$ and coronary heart disease by $4 \%$, whereas a reduction of $5 \mathrm{mmHg}$ is likely to reduce the risk of these diseases by 14 and $9 \%$, respectively (Chobanian et al., 2003). Therefore, the reduction of 6.7 $\mathrm{mmHg}$ recorded in this study suggests the possibility of aerobic dance exercise as a preventive measure and non-pharmacological treatment of hypertension. There should however be caution on the exercise intensity and duration especially for hypertensive pregnant women as this study was carried out only on women with normal BP.

A study by Papp et al. (2013) on the effect of 8 weeks of Yoga exercise on the blood pressure of healthy men and women however showed no improvement on the BP of the participants. It should be noted that the post exercise hypotension which is an acute effect of exercise is lost over time (Carpio-Rivera et al., 2016). This may explain the no effect recorded by Papp et al. (2013).

\section{CONCLUSION}

Our study recorded an increase in the SBP and DBP following 30 min of exercise, which later decreased below pre-exercise values, after 30 min rest. Our findings are in line with other studies on effect of exercise on BP, though no previous study was found on the acute effect of exercise in pregnant women. We therefore concluded that moderate intensity aerobic dance has a post exercise effect of reducing the blood pressure in pregnant women and so may be effective in controlling blood pressure in pregnancy. We suggest further study on the effect of aerobic dance in women with gestational hypertension.

\section{REFERENCES}

Artal R, O'Toole M, 2003. Exercise in pregnancy: Guidelines of the American College of Obstetricians and Gynecologists for exercise during pregnancy and the postpartum period. Br J Sports Med, 37(1). Blumenthal JA, Sherwood A, Gullette EC, Babyak M, Waugh R, Georgiades A, 2000. Exercise and weight loss reduce blood pressure in men and women with mild hypertension: effects on cardiovascular, metabolic, and hemodynamic functioning. Arch Intern Med, 160(13): 1947-1958.

Cardoso Jr CG, Gomides RS, Queiroz AC, Pinto LG, Silveira Lobo F, Tinucci $T, 2010$. Acute and chronic effects of aerobic and resistance exercise on ambulatory blood pressure. Clinics, 65(3): 317-325.

Carpenter M, Sady S, Hoegsberg B, Sady M, Haydon B, Cullinane E, 1988. Fetal heart rate response to maternal exercise. JAMA, 259: 3006-3009.

Carpenter M, Sady S, Sady M, Haydon B, Coustan D, Thompson P, 1990. Effects of maternal weight gain during pregnancy on exercise performance. J Am Physiological Soc, 30: 1173-1176.

Carpio-Rivera E, Moncada-Jiménez J, Salazar-Rojas W, SoleraHerrera A, 2016. Acute effects of exercise on blood pressure: A meta-analytic investigation. Arq Bras Cardiol, 106(5): 422-433.

Chobanian AV, Bakris GL, Black HR, Cushman WC, Green LA, Izzo JL $\mathrm{Jr}$, Jones DW, Materson BJ, Oparil S, Wright JT Jr, Roccella EJ; National Heart, Lung, and Blood Institute Joint National Committee on Prevention, Detection, Evaluation, and Treatment of High Blood Pressure; National High Blood Pressure Education Program Coordinating Committee, 2003. The Seventh Report of the Joint National Committee on Prevention, Detection, Evaluation, and Treatment of High Blood Pressure: the JNC 7 report. JAMA, 289(19): 2560-2572.

Danforth DN, 1967. Pregnancy and labor from the vantage point of the physical therapist. Am J Phys Med, 46: 653-658.

Daniel JA, 2008. Antenatal Exercises: Going through Pregnancy and Labour with Ease. Gidan Dabino Publishers, Jakara, Kano Nigeria. pp. 22.

Daniel JA, Dikki CE, Ibrahim W, 2014. Aerobic dance exercise improves blood glucose level in pregnant women with gestational diabetes mellitus. Afr J Phys Health Edu Recr Dance, 20:273-281.

Daniel, JA, Ezeugwu CC, Nwaogu EI, 2015. Effects of antenatal exercise on length of gestation among women attending antenatal clinic of the Federal Medical Centre Owerri, Southeast Nigeria. Int $\mathrm{J}$ H Rehab Sc, 4(4): 212-217.

Fagard $\mathrm{RH}, 2006$. Exercise is good for your blood pressure: effects of endurance training and resistance training. Clin Exp Pharmacol Physiol, 33(9): 853-856.

Halliwill JR, 2001. Mechanisms and clinical implications of postexercise hypotension in humans. Exerc Sport Sci Rev, 29(2): 65-70.

Halliwill JR, Buck TM, Lacewell AN, Romero SA, 2013. Post exercise hypotension and sustained postexercise vasodilatation: what happens after we exercise? Exp Physiol, 98(1): 7-18.

Hara K, Floras JS, 1995. Influence of naloxone on muscle sympathetic nerve activity, systemic and calf haemodynamics and ambulatory blood pressure after exercise in mild essential hypertension. $J$ Hypertens, 13(4): 447-461.

Higashi Y, Sasaki S, Sasaki N, Nakagawa K, Ueda T, Yoshimizu A, 1999. Daily aerobic exercise improves reactive hyperemia in patients with essential hypertension. J Hypertens, 33(2): 591-597.

Kenney MJ, Seals DR, 1993. Postexercise hypotension. Key features, mechanisms, and clinical significance. Hypertension, 22(5): 653-664.

Lockwood JM, Wilkins BW, Halliwill JR, 2005. H1 receptor-mediated vasodilatation contributes to postexercise hypotension. J Physiol, 563(Pt 2): 633-642.

Moreira WD, Fuchs FD, Ribeiro JP, Appel LJ, 1999. The effects of two aerobic training intensities on ambulatory blood pressure in hypertensive patients: results of a randomized trial. J Clin Epidemiol, 52(7): 637-642.

Nascimento L, Santos A, Lucena JM, Silva LGO, Almeida AE, Brasileiro-Santos MS, 2017. Acute and chronic effects of aerobic exercise on blood pressure in resistant hypertension: study protocol for a randomized controlled trial. Trials, 18: 250.

Papp ME, Lindfors P, Storck N, Wandell PE, 2013. Increased heart rate variability but no effect on blood pressure from 8 weeks of hatha yoga - a pilot study. BMC Research Notes, 6: 59.

Park S, Rink LD, Wallace JP, 2006. Accumulation of physical activity leads to a greater blood pressure reduction than a single continuous 
session, in prehypertension. J Hypertens, 24(9): 1761-1770.

Perales M, Mateos S, Vargas M, Sanz I, Lucia A, Barakat R, 2015. Fetal and maternal heart rate responses to exercise in pregnant women. A randomized controlled trial. Arch Med Deporte, 32(6): 361367.

Pescatello LS, Turner D, Rodriguez N, Blanchard BE, Tsongalis GJ, Maresh CM, 2007. Dietary calcium intake and renin angiotensin system polymorphisms alter the blood pressure response to aerobic exercise: a randomized control design. Nutr Metab, 4: 1.

Pinto A, Di Raimondo D, Tuttolomondo A, Fernandez P, Arnao V, Licata G, 2006. Twenty-four hour ambulatory blood pressure monitoring to evaluate effects on blood pressure of physical activity in hypertensive patients. Clin J Sport Med, 16(3): 238-243.

Pober DM, Braun B, Freedson PS, 2004. Effects of a single bout of exercise on resting heart rate variability. Med Sci Sports Exerc, 36(7): $1140-1148$.

Quinn TJ, 2000. Twenty-four hour, ambulatory blood pressure responses following acute exercise: impact of exercise intensity. $J$ Hum Hypertens, 14(9): 547-553.

Rueckert PA, Slane PR, Lillis DL, Hanson P, 1996. Hemodynamic patterns and duration of post-dynamic exercise hypotension in hypertensive humans. Med Sci Sports Exerc, 28(1): 24-32.

Shrock P, 2008. Exercise and Physical Activity during Pregnancy Glob. Libr. Women's Med, (ISSN: 1756-2228); DOI 10.3843.
Citation: Daniel JA, Nwaogu El, Okoli SC, Nzeribe EA, 2019. Acute effect of aerobic dance exercise on blood pressure of normotensive pregnant Nigerian women. Int Res J Med M ed Sci, 7(1): 28-33. 